\title{
Regionalizacija Slovenije
}

\section{Primer kompleksne socialno-geografske aplikacije v sodobnih družbenih pogojih}

\author{
Marjan Ravbar \\ Dr., Geografski inštitut Antona Melika, Znanstvenoraziskovalni center SAZU, \\ Gosposka 13, 1000 Ljubljana, Slovenija \\ e-mail: marjan.ravbar@zrc-sazu.si
}

\section{Izvleček}

Pri regionalizaciji vloga geografov ni zgolj povezana s pripravo ustrezne členitve Slovenije na ustrezna funkcijsko zaokrožena območja, marveč sodobne družbene prilike od njih zahtevajo sistematično vrednotenje variantnih členitev z vidika vzročne povezanosti oblikovanja pokrajin. Prav posebej še med regionalnim razvojem oz. učinki policentrične zasnove omrežja naselij in decentralizacije (javnih) institucij. Pričujoči prispevek govori o vlogi, učinkih in posledicah decentralizacije institucij kot instrumenta za oblikovanje uravnoteženega razvoja. $V$ njem analiziramo faktorje, ki vplivajo na uspeh regionalizacije $v$ funkciji decentralizacijske politike.

Ključne besede: reforma politično-institucionalnega sistema, regionalizacija območij, decentralizacija institucij, regionalni razvoj

\section{The Regionalization of Slovenia: An Example of a Complex Sociogeographical Application in Modern Social Conditions}

\begin{abstract}
We analyze the factors influencing the success of regionalization in the operation of the decentralization policy, in particular the formation of clear political and legal frameworks for reform process, the precise designation of strong and, if feasible, interdisciplinary commissions for administering the decentralization process, the formation of a concept of decentralized regionalization for Slovenia that aims at the even division of tasks and responsibilities including clear forms of reciprocal coordination and control among the various regional and national levels, and finally the taking of measures to guarantee the professional ability of institutions and decentralized regional associations to undertake new tasks.
\end{abstract}

Key words: reform of politically institutionalized systems, regionalization, decentralization of institutions, regional development, Slovenia 


\section{UVOD}

Pričujoči prispevek poskuša na teoretski ravni poiskati povezave med regionalizacijo oz. decentralizacijo institucij in regionalnim razvojem. Razmerja med družbenoekonomskim in institucionalnim razvojem je moč proučevati $\mathrm{z}$ dveh zornih kotov, in sicer: ali reforma hierarhične organiziranosti institucionalnega sistema državne administracije vpliva na gospodarski in družbeni razvoj in obratno: ali sta gospodarski in družbeni napredek rezultat institucionalne regulacije (Rauch, 1996). Poudarek je torej namenjen dvema spremenljivkama: spremembam v gospodarski, tehnološki in družbeni sferi ter politično izraženim težnjam po decentraliziraciji institucionalnega razvoja.

Splošna prizadevanja po nadaljnji preobrazbi obstoječe členitve pokrajinskih enot, sprožene s spremenjenim odnosom prebivalstva do regionalne pripadnosti in sočasnim spodbujanjem skladnega regionalnega razvoja so prevladujoče težnje in hkrati tudi cilj v večini dežel Evropske Unije. Evropski politiki in eksperti razmišljajo o novih pristopih pri zmanjševanju regionalnih razlik v jutrišnji EU. Zato je evropski parlament koncem leta 1998 sprejel resolucijo (Die Regionalisierung in Europa, 1998) o obvezni analizi, s katero bi primerjali regionalno organiziranost $\mathrm{v}$ sedanjih in prihodnjih članicah. Hkrati je ta resolucija priporočila uskladitev notranje regionalne organiziranosti skladno s predpisanimi skupnimi kriteriji. Kmalu pa se je izkazalo, da kljub spoštovanja vredni ideji po poenotenju kriterijev za oblikovanje enotnega modela členitve pokrajinskih enot $v$ Evropi in navkljub njeni načelni naklonjenosti, obstajajo prav tako pomembna nasprotja in predvsem praktične težave med splošno podprto težnjo po enotni regionalizaciji in oblikovanju primerljivih regij predvsem zaradi zgodovinskih razlik, družbenih interesov in stopnje gospodarske diferenciacije ter upravno-pravne raznolikosti njenih izraznih oblik. Izkazalo se je tudi, da je oblikovanje enotnega koncepta za določitev velikosti pokrajin in razmejitve pristojnosti med državo in pokrajinami praktično nemogoče. Prav tako je postalo jasno, da je oblikovanje primerne in splošno priznane definicije za oblikovanje velikosti pokrajin zelo težavno. Enake težave povzroča priprava primerjalnih kriterijev razmejevanja za raven "evropskih" regij. Doseženo je bilo le soglasje, da postopke za oblikovanje pokrajin lahko tolmačimo kot kompleksen in dinamičen proces, ki pa lahko bistveno vpliva na razvoj na srednji ravni upravljanja (npr. na področju pospeševanje skladnega regionalnega razvoja). Za racionalnejše funkcioniranje države je potrebno opredeliti prostor, ki naj določa območje pokrajine ${ }^{1}$. Samoumevno je, da je potrebno območja pokrajin določiti in oblikovati z ustreznimi predpisi ter jim na ta način zagotoviti njihovo identiteto. Ker je izenačevanje življenjskih pogojev pomemben nacionalni cilj, je neizpodbitno tudi oblikovanje enotnih (državnih) kriterijev 
za oblikovanje pokrajin. V Sloveniji "pokrajine", v administrativnem pomenu (npr. okraji, pa planske in pozneje statistične regije...) prevzemanja določenih državnih funkcij, poznamo že dalj časa. $Z$ razvojno preobrazbo države se pojavljajo še nove funkcije (npr: na področju javnih institucij), spreminjajo se tudi gravitacijska območja. Določanje velikosti in obsega pokrajin običajno temelji na homogenosti in gravitacijski pripadnosti območja, na historičnih, administrativnih, ekonomskih in funkcijskih oblikah ter velikosti naselbinskih struktur, povezanih v sistem omrežja naselij. Funkcioniranje pokrajin je odvisno še od socialno-ekonomskih prilik, od dostopnosti do tistih urbanih središč, ki so si v hierarhiji mest "priborile" vlogo razvojnih generatorjev (predvsem na področju oblikovanja (javnih) institucij, zaposlovanja in poslovno-oskrbnih funkcij in tudi od politično-administrativnih faktorjev. Položaj, velikost in obseg regij so strateškega pomena za regionalno in prostorsko politiko države.

\section{REGIONALIZACIJA ${ }^{2}$ IN DECENTRALIZACIJA ${ }^{3}$ V FUNKCIJI POSPEŠEVANJA REGIONALNEGA RAZVOJA}

Sodobni koncepti oblikovanja pokrajin, kot avtonomnih političnih in/ali administrativnih tvorb, imajo v Sloveniji svoje zametke že v zasnovi policentričnega razvoja, v Evropi pa so povezane z oblikovanjem strukturnih in kohezijskih skladov. Oba primerljiva koncepta sta stara dobrih trideset let. V marsičem sta povezana $\mathrm{z}$ odstopanjem od tradicionalnih pogledov na oblikovanje pokrajin kot najnižje neposredne ravni države s politično reprezentativnostjo, ki je izražena z voljenimi predstavniki. Nove ideje bolj izhajajo iz uveljavljanja zamisli, da javnopravne teritorialne skupnosti same uravnavajo družbeni razvoj, ki ga razvijajo v pretežni meri z lastnimi razvojnimi potenciali. Prav zato je kohezijska politika poskuse oblikovanja enotnih definicij za pokrajino še razrahljala na bolj ali manj institucionalno raven. Vodenje skupne regionalne politike, namenjene preprečevanju regionalnih nesorazmerij postavlja vlogo pokrajin in njenih institucij v enakovreden položaj z državnimi institucijami, ki so potemtakem osvobojene kontrole nad izvajanjem regionalne politike. Zasledovanje tega cilja daje podporo regionalnim in tudi lokalnim političnim skupnostim.

Uspešen regionalni razvoj ni več $\mathrm{v}$ tolikšni meri odvisen od tehničnih inovacij in ustvarjalnega okolja, kot so to mnogi avtorji še nedavno zagovarjali, ampak je $v$ marsičem povezan tudi z oblikovanjem in pospeševanjem določenih organizacijskih oblik decentralizirane demokratizacije. Z uvajanjem regionalizacije dobivajo $\mathrm{v}$ sodobni razvojni politiki institucije ${ }^{4}$, namenjene regionalnemu razvoju odločujoč vzvod, naperjen tudi proti centralizaciji države. Re- 
gionalizacija države s pomočjo decentralizacije institucij nastopa kot impulz motivacija - in osrednja oporna točka za skladen družbeni razvoj.

V družboslovnih vedah stopa $\mathrm{v}$ ospredje "nova institucionalna ekonomija" kot "Main Stream" razmišljanja in raziskovanja. Izhaja iz analize vplivov institucionalnih sprememb $\mathrm{z}$ vidika regulacijskih, spodbujevalnih in normativnih sistemov na gospodarsko obnašanje in s tem na razvojni (ne)uspeh. V razvojni politiki postajajo potemtakem institucionalne reforme oporna točka ali instrument, ki običajno sproža gospodarski napredek in izboljšanje življenjskih pogojev. Večina razvojno-političnih organizacij namreč z razvojem večpartijske demokracije terja še decentralizacijo politične in birokratske moči in privatizacijo kot globalni odgovor na državno moč. V razvojni praksi zato "novo institucionalno ekonomijo" obravnavamo skozi prizmo kompleksnih učinkov na razvojne procese. Pri tem je reforma institucionalne sfere pomemben del, sicer zelo obsežnega razvojnega procesa družbene diferenciacije. Na prvi pogled reforma institucionalnega sistema nastopa veliki meri neodvisno, $\mathrm{v}$ resnici pa $\mathrm{v}$ gospodarskem in družbenem razvoju odigrava zelo pomembno spremenljivko. Pobudnikom novih razvojnih paradigm (npr. Northu, 1992 in Beierju, 1995) gre zasluga, da pri zagotavljanju skladnejšega regionalnega razvoja poudarjajo vedno večji pomen institucionalnim vidikom družbenega razvoja. Spodbujanje in usmerjanje regionalnega razvoja s pomočjo državnih regulacijskih mehanizmov, čigar kratko izražena programska misel je bila "Get the Institutions Right", je nadomestil ali bolje povedano dopolnil neoklasični in redukcionistični moto "Get the Prices Right". Ta nova pozornost institucionalnim vidikom, novim regulacijskim oblikam in njihovem učinkovanju na gospodarski in družbeni razvoj je z razvojno-teoretskega kot tudi z razvojno-praktičnega pogleda za pozdraviti. Prizadevanjem za prevrednotenje naraščajočega pomena institucionalne dimenzije $\mathrm{v}$ regionalnem razvoju gredo na roko številne praktične izkušnje, ki so uspešnost institucionalnega razvoja s praktičnimi primeri nesporno dokazale. Npr. Bruselj je zrasel v veliko mesto šele, ko je postal središče evropskih institucij, ali drug primer: Luksemburg je še vedno za evropske razmere majhno mestece. Je pa predvsem zaradi neverjetne koncentracije bank, pa tudi zaradi velikega števila drugih evropskih institucij, najbolj bogato mesto in država z največjo kupno močjo na prebivalca na svetu. Podobnih primerov je še veliko in politična prizadevanja to samo dodatno potrjujejo ${ }^{5}$.

Diskusija o vlogi institucij v razvojnem procesu se ne navezuje zgolj na vprašanje pomembnosti institucionalne dimenzije. Ta je nesporna. Nanaša se še na razmerja oz. odnose med institucionalno in ekonomsko in/oz družbeno sfero ali povedano plakativno, na razmerje med institucijami in razvojem. Kot primer navajamo agrarno družbo, temelječo na bolj ali manj družinskih odnosih, za katero so veljali povsem drugačni regulacijski mehanizmi kot npr. za sodobno, visoko razvito (post)industrijsko in močno urbanizirano družbo, kjer 
so ti odnosi več ali manj anonimni in zato kompleksnejši. Povezanost med stopnjo tehnološkega razvoja in načinom institucionalne uravnave je prav tako predmet razprav. Vprašanje o dejavnikih, ki vplivajo na optimalno velikost pokrajin ter obliko institucionalnih sistemov in obratno, kako ekonomska in družbena sfera učinkujeta na institucionalne vsebine, ostaja zaenkrat na mnogih področjih še neodgovorjeno.

Tudi Slovenija poskuša v skladu s strategijo približevanja deželam EU izvajati decentralizacijsko politiko, ki jo zaenkrat na pravno formalni ravni vzpostavlja le zakon o pospeševanju skladnega regionalnega razvoja in temelji na konceptu zagotavljanja enakomernejših pogojev na območju celotne države s pomočjo instrumentov regionalne politike in medsebojnega sodelovanja. Skozi izvajanje državnega razvojnega programa do leta 2006 mu poskušajo slediti pristojna nacionalna ministrstva, pod pogojem, da se v tem času usposobijo pristojna regionalna združenja. Tej politiki pa morajo slediti še ostale (u)pravne in politične podlage. Kar pa je najbolj pomembno: s smotrno in uspešno izvedbo decentralizacijske politike so povezani resnično močni nosilci regionalne politike ter obvezujoči, prepričljivi in izvedljivi skupni razvojni programi. Pristojna ministrstva običajno nasprotujejo uveljavljanju decentralizacije in $\mathrm{v}$ veliko primerih $\mathrm{z}$ administrativnimi (in drugimi) ovirami zavlačujejo prenos pooblastil. Aktualne politične rešitve vzbujajo bojazen po preveč administrativnem urejanju slovenskih pokrajin. V tem primeru je "ustanavljanje" pokrajin kot novih političnih skupnosti oz. druge stopnje lokalne samouprave $\mathrm{v}$ bistvu paradoks, ker bodo tako zasnovane pokrajine predstavljale neko posebno modaliteto $\mathrm{v}$ tem procesu, saj bodo odstopale od splošno priznanih definicij za oblike pokrajine in tudi ne bodo imele ustreznih institucij na regionalni ravni. Izključevanje institucij, kot razvojnih faktorjev, je v nasprotju s historičnim delovanjem le-teh in vodi $\mathrm{k}$ temu, da realni institucionalni sistemi ne bodo v kontekstu s konkretnimi gospodarskimi in regionalnimi potrebami.

V majhni, vendar mozaično izredno pestri in raznoliki državi, kakršna je Slovenija, so možnosti oblikovanja pokrajin omejene. Kljub vsemu je možnih več načinov oblikovanja regionalizacij. Posplošeno povedano, lahko Slovenija izbira med:

- $\quad$ administrativno členitvijo ${ }^{6}$

- členitvijo na podlagi združevanja obstoječih lokalnih skupnosti ${ }^{7}$

- regionalno decentralizacijo ${ }^{8}$

- in politično regionalizacijo s pomočjo regionalne avtonomije (institucionalni regionalizem) ${ }^{9}$.

Vsekakor pa je potrebno paziti, da se katerokoli od naštetih različic regionalizacij obravnava v povezavi z modelom "plitvega" in decentraliziranega omrežja mest znotraj funkcijsko in gravitacijsko povezanih mestnih regij, ki temelje na sodobnih principih mrežnega povezovanja razvojnih polov in večstopenj- 
ske pripadnosti prebivalstva (Ravbar, 2002) - kot hierarhije vrednot, pri čemer mora država za dosego idealnega modela težiti k zagotavljanju regionalne avtonomije kljub temu, da členitev na pokrajinske enote ni vedno homogena in da razmere niso povsod trdne. Inovativni karakter oblikovanja tovrstne regionalizacije je jasno poudarjen in ga ni moč primerjati s historičnim razvojem institucij na srednji ravni. Države, ki so še do nedavnega ustanavljale institucije na srednji ravni kot vmesni člen za krepitev moči centralne oblasti, to počno danes zaradi izenačevanja pogojev v regionalnem razvoju.

\section{SOCIALNOEKONOMSKI DEJAVNIKI DECENTRALIZIRANE REGIONALIZACIJE}

Pomembni dejavniki politično-institucionalnega sistema, ki spodbujajo ali zavirajo decentralizirano regionalizacijo institucij, posredno s tem pa tudi regionalni razvoj so:

1) Moč centralne oblasti: Če je nacionalna oblast močna in učinkovita ter njeno delovanje razpoznavno, potem je s stremljenji za regionalizacijo težko prodreti. Če pa so centralne oblasti v krizi, potem je njeno moč bistveno težje ohranjati in je njena pozicija nasproti regionalističnim težnjam ljudi omajana. Pod temi pogoji je decentralizacija lažje izvedljiva in priložnosti za oslabitev centralne oblasti večje.

2) Ohranjanje obstoječih institucij je usmerjeno k utrjevanju dejanskega stanja z namenom konsolidacije obstoječih pozicij, ki slede načelom, da kakršnekoli spremembe pomenijo tveganje in zavajanje. Zagovorniki centralizacije branijo svoje pozicije z utemeljitvijo češ, da bo sprememba povzročila destabilizacijo obstoječega sistema in opuščanje obstoječih privilegijev. Centralne oblasti vedno znova utemeljujejo, da pokrajine ali skupnost lokalnih skupnosti niso sposobne opravljati zastavljenih nalog (predvsem tistih finančne narave) (Beier, 1995).

3) Sektorska in kulturna identiteta: nekatera območja imajo tudi v Sloveniji izrazito izraženo sektorsko in kulturno identiteto. Naravnogeografska pestrost, raznolikost pokrajinskih enot in družbenogeografska heterogenost jo samo dopolnjujejo. Kulturna in naravnogeografska pestrost pogosto sproža željo med ljudmi po močnejši regionalni samostojnosti. Praviloma gre za periferna in obmejna območja. Le-ta pričakujejo prenos nekaterih dejavnosti (predvsem kulturno-izobraževalnih in socialnih) z namenom, da decentralizacija pomeni odpiranje in zaupanje $\mathrm{v}$ sistem povezovanja $\mathrm{z}$ urbanimi središči višje ravni. Stremljenja po ohranjanju sektorske in kulturne identitete in spoštovanje regionalne pripadnosti nima podcenjeval- 
nega prizvoka in vztrajanje pri tem je zelo pomemben element, ki koristi centralistični in vertikalno zasnovani organizaciji državne uprave oz. oblasti.

Postopki za uvedbo decentralizacije so v pretežni meri poznani (Rondinelli in drugi, 1989), prav tako tudi prednosti in opozorila pred nezaželenimi učinki. Vendar učinkov ni mogoče prikazovati enostransko in jih analizirati s statističnimi metodami, saj so ponavadi rezultanta specifičnih in lokalnih prilik. Prednosti in slabosti decentralizacije so odvisne velikega števila med seboj prepletenih in kompleksnih elementov. Odločujočo vlogo imajo kljub vsemu historičnokulturne specifičnosti, gospodarske prilike, prometno-geografsko, družbeni in politični pogoji, itd. Analiza elementov je zasnovana tako, da reforma institucionalnega sistema izhaja iz analize dejavnikov vpliva, na podlagi katerih poskušamo izluščiti pozitivne učinke in opozoriti na morebitne pasti. Model, kot ga prikazuje slika, poskuša v zaključku nakazati še nabor možnih instrumentov za preprečevanje centralizacije.

$\mathrm{Na}$ reformo institucionalnega sistema vpliva vrsta elementov, ki so povezani z (ne)uspehom zastavljenih ciljev. Sem sodijo zlasti:

- Oblikovanje jasnih političnih, institucionalnih in (u)pravno administrativnih okvirov za začetek reformnega procesa,

- Natančna navedba močnih, po možnosti medresorskih nosilcev za upravljanje in koordinacijo kompleksnega procesa decentralizirane regionalizacije,

- Podrobna razdelava koncepta decentralizirane regionalizacije Slovenije s ciljem enakomerne porazdelitve nalog in odgovornosti, kot so npr. jasne oblike medsebojne (horizontalne in vertikalne) koordinacije ter vzajemne kontrole med regionalnimi in državno ravnijo,

- Opustitev podrobnih in fazno naravnanih prenosov programov na državni ravni, s poimenovanjem strokovnih, administrativnih in pravnih korakov za prenos programiranja in odgovornosti na udeležence $\mathrm{v}$ regionalnih skupnostih;

- Ukrepi za zagotavljanje strokovne usposobljenosti institucij in decentraliziranih regionalnih združenj za prevzem novih nalog.

Politična volja je torej odločilna za začetek procesa decentralizacije in na sam proces lahko vpliva mimo obstoječega, centralizirano zasnovanega instucionalnega sistema. V slovenskih razmerah le-ta običajno posega po historičnih vzorih in po pravilu izhaja iz polpreteklih izkušenj, predvsem iz nikoli do konca zaživetih planskih regij, dodatno vzpodbujenih s (pre)ozko lokalno politično iniciativo. Tem dejavnikom pripadajo zlasti relativno močne regionalne (lokalne) elite, ki želijo s pomočjo decentralizirane kontrole vzpostaviti legitimnost za izvedbo ozkih regionalističnih interesov. Kjer je volja po uveljavitvi 


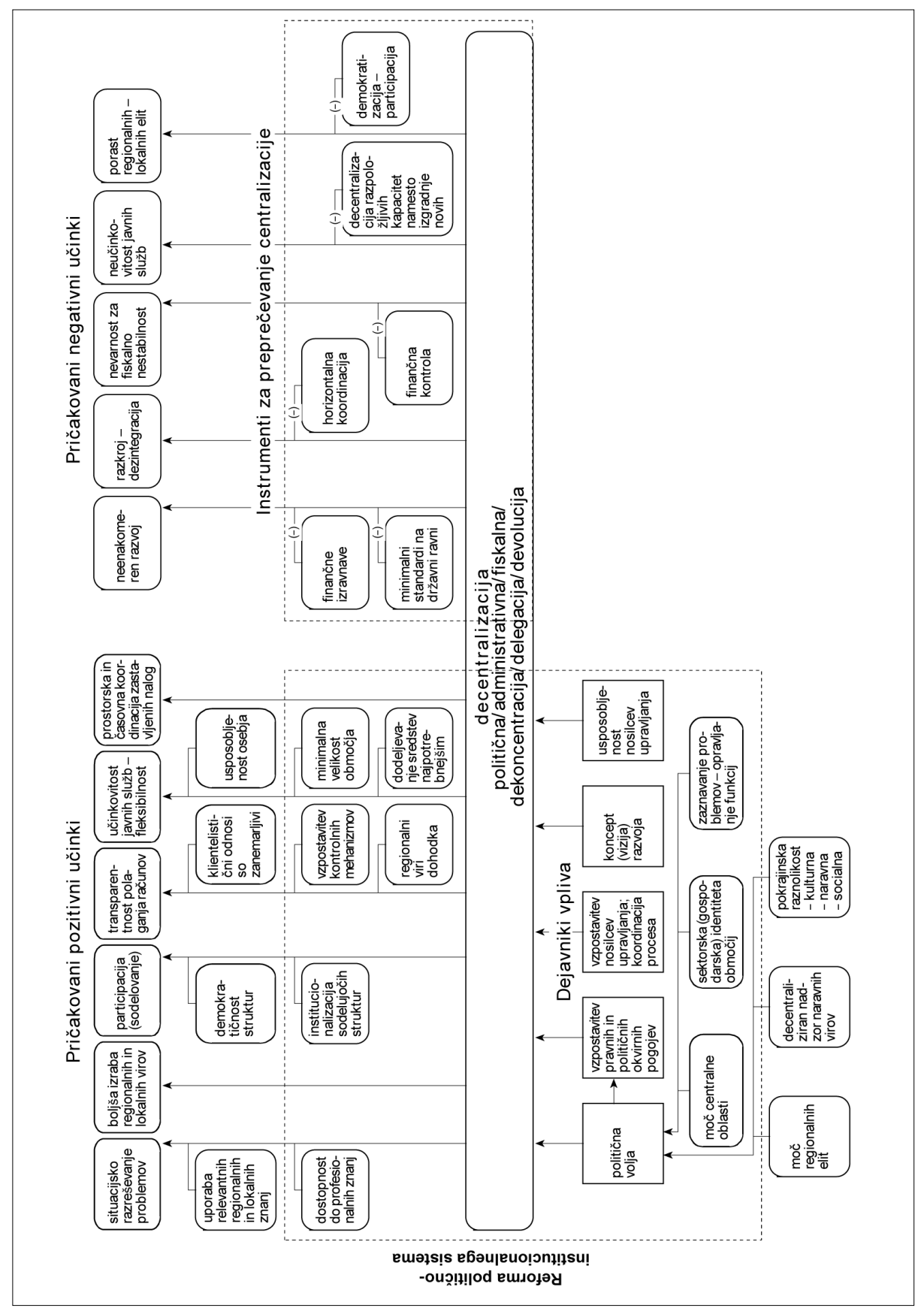

Slika 1: Model dejavnikov decentralizacije in vplivi na regionalizacijo države (priredba po Rauch, 1996) 
tovrstne moči, potem primanjkuje moči za uveljavitev skupnih narodnogospodarskih interesov. Zato tudi stremljenja za vzpostavitvijo druge stopnje lokalne samouprave potekajo že skoraj celo desetletje.

Uspešnost reforme politično institucionalnega sistema je $\mathrm{v}$ naslednjih elementih povezana s cilji oz. pričakovanimi pozitivnimi učinki decentralizacije:

- Cilj decentralizacije institucij je usmerjen k problemskemu razreševanju ključnih problemov iz lokalnega okolja. Zato so odločitve povezane s specifičnimi okoliščinami okolja in so tendenčno naravnane k učinkovitejšemu razreševanju in še boljši izrabi lokalnih resursov. To drži predvsem za tista področja odločanja, kjer že obstajajo lokalna znanja. Poleg tega je pri oblikovanju decentraliziranih sistemov pomembna še skrb za ohranjanje dostopnosti do profesionalnih specialnih znanj.

- Predpogoj za uspešno decentralizacijo je, da morajo odločitve sloneti na občutku soudeležbe občanov. Čim bližje so institucije prizadetim ljudem, tem bolj odločitev za decentralizacijo ugaja ljudem in tem enostavneje je neposredne ukrepe mogoče tudi začeti izvajati. Decentralizacija vsebuje, vendar ne avtomatično, več participacije. Marsikje so lokalne politične strukture daleč od demokratičnih pravil in bolj ali manj bolj avtoritativnejše, kot oblasti na nacionalni ravni. Decentralizacija zato odpira priložnosti za lokalno demokracijo (Stockmayer, 1999), predvsem z institucionalizacijo participativnega sodelovanje $\mathrm{v}$ planerskem procesu.

- Podobne utemeljitve za decentralizacijo držijo tudi v povezavah med decentralizacijo in transparentnostjo odločitev, kot tudi v javni odgovornosti oblastnih organov. Čim bližje so odločitve občanom, tem lažja je kontrola in vzpostavljanje občutka odgovornosti pri konkretnih dogovorih. Če pa gre vendarle za napačno uveljavitev decentraliziranih odločitev, je ta očitno posledica netransparentnega ravnanja nasproti prizadetemu prebivalstvu. Ta je običajno najbolj zaznavna na podeželju. Tem pomanjkljivostim se je moč izogniti npr. s pomočjo neformalnih razvojnih koalicij v skupnostih medobčinskega sodelovanja na ravni NUTS 4 ali skozi porazdelitev razvojnih potencialov. Sem sodijo še mehanizmi za krepitev ciljno naravnane (finančne) transparentnosti. V tej zvezi je zelo pomembno, da se vsaj del finančnih sredstev zbere s pomočjo lokalnih virov. Tam so občani praviloma bolj budni, kot tam, kjer se črpajo "tuji" finančni viri.

- Decentralizirana regulacija je spodbuden impulz za učinkovitejšo delovanje javnih služb najprej z vidika skrajševanja "instančnih" poti in tudi zaradi višje stopnje fleksibilnosti ravnanja uprave. Takšne potencialne prednosti učinkovitosti javnih služb je mogoče zagotoviti z ustrezno kvalificiranim personalom za številčne regionalne / lokalne pristojnosti. 
- Decentralizacija je predpogoj za sektorsko, vedno bolj razširjeno koordinacijo investicij na področju služnostnih dejavnosti na regionalni oz. lokalni ravni. Le-te pa so običajno uspešnejša, če je avtonomija odločanja prepuščena nosilcem javnih funkcij na regionalni ravni.

- Decentralizacija pa lahko izzove tudi nezaželene učinke:

- Neenakomeren razvoj in regionalne disparitete se lahko poglobijo, če se s sredstvi, pridobljenimi s pomočjo subsidiarnosti upravlja brez soudeležbe prizadetih. Finančne izravnave in nacionalni minimalni standardi pri javnih storitvah so instrumenti, ki težnjam po poglabljanju regionalnih disparitet postavijo "pregledne" meje.

- Pri visoki stopnji regionalne avtonomije lahko vzbuja skrb za preveliko dezintegracijo države. Konkurenca med regionalnimi združenji in centralizirano državno upravo ter investicijami ima lahko destruktivni značaj, npr. podvajanje različnih služb. Institucionaliziranje mehanizmov na horizontalni ravni in koordinacija med regionalnimi oblastmi in državo lahko tovrstne dezintegracijske težnje zadrži v sprejemljivih mejah.

- Finančna ministrstva imajo bojazen za izgubo fiskalne stabilnosti, če je množica regionalnih združenj avtonomna pri najemanju kreditov in določanju obsega izdatkov. Samo skozi centralizirano finančno kontrolo je mogoče izvajati uspešno makroekonomsko naravnanost s stabilizacijskimi cilji.

- Decentralizacija vzbuja še skrb za neučinkovito razbohotenje javnih služb, birokracije, ki vodi k podvajanju oblastnih ustanov.

- Decentralizirana kontrola nad resursi lahko vodi k povečevanju moči regionalnih elit, ki se povečuje skozi priložnosti zapostavljanja določenih socialnih grup, vodi pa tudi k zmanjševanju javnih obveznosti.

- Veliko je tudi dvomov, ki govore proti pospeševanju decentralizacijske politike, saj se pogosto pojavljajo vprašanja o smotrnosti pretirane razdrobljenosti decentraliziranih državnih funkcij v povezavi s konkretnimi družbenimi pogoji in cilji.

Zgodovinski in prostorski pogoji za uvajanje decentraliziranega političnega in administrativnega sistema v Sloveniji po osamosvojitvi niso ugodni. Tudi decentralizacija sama po sebi še ni nikakršen prispevek za pospeševanje razvoja ob hkratnem zmanjševanju regionalnih disparitet. Decentralizirana kontrola resursov lahko pod določenimi družbenimi pogoji nerazvitost, obubožanje, propad resursov razkroji in konflikte še poostri. Instrumenti za preseganje stanja so povezani s finančnimi izravnavami, decentralizacijo razpoložljivih kapacitet ter horizontalno koordinacijo in participacijo. 


\section{ZAKLJUČEK}

Regionalizacija in decentralizacija $\mathrm{v}$ vsakem primeru vsebujeta prerazdelitev moči tj. izgubo moči centralnih državnih organov. Potemtakem decentralizirane oblike regulacije posledično pomenijo prenos moči določenih socialnih grup na druge. Njihov realni prenos pa mora biti predhodno dogovorno (so)oblikovan. Predhodno je potrebno ugotoviti, kakšno moč želijo imeti pokrajine in predvsem, kako z njimi tudi upravljati. Uveljavitev in izvedljivost decentralizacije je odvisna od družbenih pogojev, od faktorjev vpliva in predvsem od politične volje za spremembo institucionalnega sistema.

Zagovorniki decentralizacije se pritožujejo, da je zato krivo pomanjkanje politične volje. To je brez dvoma odločujoč dejavnik za uveljavitev procesa decentralizacije. Izhajajoč iz gornje podmene, da ni lahko prepričati, da je prenos pristojnosti in kontrole nad resursi enostavna in družbenopolitično naivna naloga. $\mathrm{V}$ tem primeru je praktično nemogoče pridobiti politično voljo za uveljavitev decentralizacije. Porazdelitev moči na decentralizirane instance je vselej sporen politični proces pri katerem vsak posamezen korak med zagovorniki in nasprotniki sproži medsebojne borbe. Kako močna je $\mathrm{v}$ neki državi politična volja, ki zagovarja koristi decentralizacije je odvisno od vrste vplivnih faktorjev med katerimi izstopa ustrezna strokovna priprava za reformo institucionalnega sistema in seveda ekonomski dejavniki ter družbena razmerja moči.

Decentralizacija ni sama sebi namen. Decentralizarana regionalizacija tudi sama po sebi ni boljša kot centralizirano upravljanje. Prednost decentralizacije je v konkretnejšem poznavanju pogojev za merjenje potreb prebivalstva od tistih, ki jih lahko ponudi država različnim socialnim in družbenim skupinam. Po drugi strani decentralizacija tudi lahko vodi k povišani stopnji korupcije, bogatenju lokalnih elit in množičnejšemu obubožanju kar tudi ni v podporo decentralizaciji. Decentralizacija je torej instrument, ki lahko bodisi v kontekstu socialno-ekonomskega razvoja pospešuje ali pa tudi zavira določene segmente družbenega razvoja. Regionalna porazdelitev resursov vpliva na možnost bodisi centralne bodisi decentralizirane kontrole. Če je ekonomska podlaga državnih prihodkov koncentrirana na regionalni ravni, potem je centralistična oblast preglednejša kot tam, kjer je gospodarsko moč decentralizirana. Načela subsidiarnosti je lažje usmerjati na podlagi celokupne gospodarske moči države, kot pa s pomočjo moči lastnih virov v mnogo manjših regionalnih skupnosti.

Regionalizacija Slovenije pa je vendarle impulz - motivacija - za evropsko integracijo, ki je vsekakor tudi v nacionalnem interesu, saj močna urbana središča v neposredni soseščini (npr. Trst, Gorica, Gradec, Celovec, ...) lahko dezintegrirajo težnje po skladnem regionalnem razvoju v Sloveniji. Obstoj pokrajin in močnih urbanih središč na obmejnih območjih je odločujoči dejavnik 
za uravnavanje gravitacijske privlačnosti velikih sosednjih mest, ki so historično, tradicionalno in ekonomsko-geografsko povezana s slovenskim življem to- in onstran meje. Naraščajoči pomen regionalnih in prostorskih kot endogenih razvojnih dejavnikov je danes razpoznan. Vendar je gonilno silo v regionalnem razvoju moč vzpostaviti na različnih ravneh, kar kaže primer novih instrumentov gospodarskega razvoja, uporabljenih na depresivnih industrijskih območij (npr. Zasavje), ki se sublimirajo v razvojnih središčih nacionalnega pomena. Nobenih "a priori" razlogov ni, da se funkcionalne prostorske enote ne bi skladale z upravnimi tvorbami. Pomembnejše bi bilo zagotoviti, da doslej sicer še nedorečena središča nacionalnega pomena ustvarjajo pogoje za uspešnejšo regionalno politiko na nad-lokalni ravni, kot so jo doslej. Optimiranje velikosti regij je manj pomembno.

Regionalizacijo, povezano z decentralizacijo institucij, je treba v Sloveniji definirati kot proces, čigar cilj je uveljavitev avtonomne izvršilne oblasti pokrajin kot pogoja za hkraten razmah ustvarjalnosti sub-nacionalnega, vendar nad-lokalnega pomena. Običajno jo sproži gospodarsko prestrukturiranje za razmah regionalne identitete in solidarnosti. Za to pa je potrebna politična volja in izhodiščni regionalni razvojni potenciali: že obstoječe razvojne institucije ali/in nove za nov razvojnih razmah. Nenazadnje, pri odpravljanju regionalnih disparitet je pomembna tudi mobilnost institucij. $\mathrm{V}$ določeni meri je regionalizacija del gibanja s težiščem, ki zagovarja enostavnejše upravljanje lokalnih zadev in je hkrati motiv - razvojno gibalo (v praviloma manj razvitih) območjih. Izraža se s spreminjanjem funkcij obstoječih institucij na srednji ravni. Če te funkcije smatramo kot vezni člen državne uprave v obliki specifičnih institucij, potem so le-te upravičene. Ustrezna regionalizacija institucionalnih prevzemov je povezana s podporo dotičnemu območju in njihovim lastnim interesom, najprej seveda socialnoekonomskim, toda vedno v kontekstu kulturne in narodnogospodarske perspektive.

\footnotetext{
${ }^{I}$ Pokrajina ali regija je najbolj pogosto predmet prostorskega urejanja in jo ponavadi tvori heterogena teritorialna enota s skupnimi narodnogospodarskimi, geografsko prometnimi in zgo-dovinsko kulturnimi pogoji in tradicijami. Navadno je to gravitacijsko polje njenega največjega urbanega središča. Tako oblikovana regija je enotno vodena in je gospodarsko zaokrožena celota, s čimer se pri njenih prebivalcih ustvarja občutek pripadnosti in odgovornosti za stvari skupnega pomena. Pokrajina je običajno odgovorna za poln razvoj lastnih gospodarskih resur-sov, za ohranjanje proizvodnih možnosti in ustvarjanje bogastva. Zato je kriterij sposobnosti samostojnega ekonomskega preživetja in nadaljnjega razvoja prevladujoč kriterij pri zasnovi in fizičnem omejevanju neke regije. Dodatni pomen pa pojem regije dobi v prostorskourejevalskem smislu, kjer je govora o specifičnih (funkcionalnih) regijah in o celostnem regionalnem razvoju, ki je dosežen z optimalnim prekrivanjem specifičnih naravno geografskih značilnosti, ekonomsko-geografskih pogojev in upravno-administrativnih enot.
} 
${ }^{2}$ Regionalizacija je proces, katerega cilj je oblikovanje pokrajin. Pokrajina ali regija (iz lat. "regio") pomeni določen del zemeljskega površja. Večina leksikonov jo označuje kot teritorialno enoto, ki ima vrsto specifičnih in individualnih potez. Pokrajino lahko poimenujemo kot administrativno, ekonomsko in naravno enoto ali ozemlje, na katerem prebiva določena družbena skupnost. V geografiji nam predstavlja del površja, ki se od ostalih razlikuje glede na posebne naravne in družbene razmere. Analize kažejo, da je regionalna specifičnost največkrat rezultat povezovanja, prepletanja in kombiniranja posameznih naravnih in družbenih pojavov in dejavnikov tako, da dajejo ozemlju določeno razpoznavnost, svojskost in celovitost. Zaradi spreminjanja dejavnikov in glede na to, da se ob tem spreminjajo tudi odnosi med dejavniki, ki tvorijo regionalni kompleks, se regije preobražajo tudi glede na doseženo razvojno stopnjo ekonomskega napredka.

${ }^{3}$ Decentralizacija je proces, kjer država v kar največji možni meri del svojih funkcij prenese na nižje organe (Verbinc, 1979), ki so z državnim središčem sicer povezani, vendar pri odločanju in izvrševanju relativno samostojni. Pomeni torej prenos moči odločanja, odgovornosti in kontrole finančnih in človeških virov iz državne na nižje razvrščene ravni oz. samostojne organizacijske enote ali javnopravne družbenopolitične skupnosti, ki so občanom bližje. Gre za dejavnosti javnih institucij, ki jih država z zakonom prenese $v$ izvirno pristojnost regionalnim skupnostim, stem da jim zagotovi sredstva in zagotovi nadzor.

${ }^{4} \mathrm{Z}$ zakonom ali normami nastala ustaljena oblika odnosov med ljudmi. Javna, organizirana skupnost ljudi za opravljanje kake dejavnosti skupnega pomena: npr. gospodarske, izobraževalne, kulturne, vzgojne, znanstvene, zdravstvene... (SSKJ,1997)

${ }^{5}$ gl. npr.: Ravbar, M., 2002: Slovenija v Evropski uniji? Preko večje mobilnosti institucij do manjših razlik med slovenskimi pokrajinami.Radio Slovenija - tretji program, Program Ars, Trojna spirala, 28. novembra 2002 ali Marinkovič, I., 2002: Boj za središče Srednje Evrope, Delo, 13. avgusta, str. 3.

${ }^{6}$ Pod administrativno regionalizacijo razumemo oblikovanje ustanov in neobhodnih oblastnih organov izven administrativnega središča države. Tu država, kljub temu, da so ta območja opremljena $z$ določeno avtonomijo izvaja svojo kontrolo podrejenih z regulacijo instrumentov svojega ravnanja, čigar funkcije ali del teh funkcij je namenjen tudi pospeševanju regionalnega in gospodarskega razvoja in temu namenu je podrejena mobilizacija lokalnih političnih skupnosti in gospodarskih združenj. (primer: ZRN je kot zvezna dežela sestavljena iz regij, ki obstoje znotraj velikih zveznih dežel. Gre za administrativno regionalizacijo (113 planskih regij znotraj 12 dežel). Znotraj EU poznamo administrativno regionalizacijo še v Grčiji, Angliji in Švedskem ter tudi v Bolgariji, Estoniji, Madžarskem, Litvi, Slovaškem in deloma tudi v Sloveniji.

${ }^{7}$ Obstoječe lokalne skupnosti stremijo, da okrepijo svoje obstoječe funkcije. Gre za razširitev in prevzemanje njihovega kompetenčnega obsega in njihovega polja delovanja skozi skupno sodelovanje na širših regionalnih okvirih. Ta vrsta regionalizacije se razlikuje od administrativne v tem, da regionalizacija poteka s pomočjo nekaterih decentraliziranih institucij, ki jih lokalne skupnosti v okvirih lastnih pooblastil opravljajo. Takšen način regionalizacije je uveljavljen $v$ sedmih državah EU (npr. na Danskem, Finski, Irski, Portugalski ter v Romuniji).

${ }^{8}$ Kot regionalno decentralizacijo označujemo vzpostavljanje institucij, čigar naloga je zagotavljanje subsidiarnosti lokalnim skupnostim. Pokrajina na ta način ohranja specifično instuicionalno obeležje. Pečat ji daje aplikacija splošnih predpisov, uredb..., značilnih za določeno skupnost. Zato tvori svojstveno kategorijo družbenopolitične skupnosti, ki enotne pravne norme oz. kompetence (pristojnosti) prilagaja lastnim specifičnostim, ki v pomembnih in bistvenih delih uravnavajo gospodarski in regionalni razvoj. Četudi se teritorialna organiziranost spreminja, kljub temu pokrajine sestavljajo enotno upravno-pravno skupnost.

${ }^{9}$ Kljub temu, da je regionalna avtonomija cilj decentralizacije institucij in vsesplošno sprejeto načelo, je implementacija vzpostavljena le v peščici evropskih držav in še ta v številnih različicah. S pravnega vidika razlikujemo politično regionalizacijo regionalne decentralizacije, $k i$ 
se izraža s prenosom zakonodajne oblasti na regionalna združenja na podlagi obširnih pristojnosti (določenih navadno z zakonom). Vsebina je podana $v$ ustavnih določbah in te so zajamčene $v$ izvršilnih oblasteh. Politična regionalizacija obvladuje celotno teritorialno sfero v Španiji, Italiji in Belgiji, deloma pa tudi v Veliki Britaniji. Politična regionalizacija je z različicami prisotna tudi $v$ državah z zvezno ureditvijo. To običajno sproža politično asimetrijo in podvaja institucije kljub temu, da obstajajo številne oblike institucionalnega sodelovanja s centralno oblastjo. Politična regionalizacija praviloma nima svojih prvobitnih vzrokov v zagotavljanju ekonomske kohezije, ampak je običajno odraz šibkosti nacionalne integracije, ki vzpodbuja regionalizme (npr. Katalonija in Baskija v Španiji, Korzika v Franciji, Flandrija v Belgiji...)

\section{Uporabljena literatura:}

Beier, C., 1995: Dezentralisierung und Entwicklungmanagement. Beobachtungen zur politisch-administrativen und zur wissenschaftlichen Kommunikation:ein systemtheoretischer Versuch. Saarbruecken.

Die regionalisierung in Europa, 1998: http://www.europa.eu.int/ workingpapers /regi /pdf/108axx.pdf

North D., C., 1992: Institutionen, institutioneller Wandel und Wirtschaftsleistung. Tuebungen: C.B. Mohr

Rauch, T., 1996: Laendliche Regionalentwicklung im Spanungfeld zwischen Weltmarkt, Staaatsmacht und kleinbaeurlichen Strategien. Saarbrucken : Verlag Entwicklungspolitik Breitenbach.

Rauch, T., 2001: Dezentralisierung ist kein Allheilmittel! - Zur Notwendigkeit einer kontextspecifischen Dezentralisierungspolitik am Beispiel der Komunalentwicklung in Suedafrika. Geographica Helvetica, Jg 56/1, str.13-26.

Ravbar, M., 1994: Država velikosti regije. - Razgledi - Časopis za umetnost, družbo in humanistiko, št 19 (1026), 14. oktobra (1994), str:18-19.

Ravbar, M., 1997: Dileme in cilji regionalne politike v luči oblikovanja pokrajin (Nekaj raziskovalnih hipotez). IB revija, št: 9-10-11, let. 31, Ljubljana, (1997), str. 3-5.

Ravbar, M., 1997: Slovenske pokrajine: Med lastnimi interesi in politiko regionalnega razvoja. IB revija, št: 9-10-11, let. 31, Ljubljana, (1997), str. 18-26.

Ravbar, M., 2002: Sodobne težnje v razvoju prebivalstva in delovnih mest pot k sonaravnemu in decentraliziranemu usmerjanju poselitve v Sloveniji. IB revija za strokovna in metodološka vprašanja trajnostnega razvoja, št. 1, let. 36, str. 12-42.

Rondinelli, D. A., McCouough, J. S., \& Johnson, R. W., 1989: Analysing Decentralisation Policies in Developing Coutries: A Political-Economy Framework. V: Developement and Change 20, str: 57-87.

Stockmayer, A., 1999: Decentralisation: Global fad or recipe for sustainable local Developement? V: Agriculture and Rural Development VI/1, str: 3-6. 


\title{
THE REGIONALIZATION OF SLOVENIA: AN EXAMPLE OF A COMPLEX SOCIOGEOGRAPHICAL APPLICATION IN MODERN SOCIAL CONDITIONS
}

\begin{abstract}
Summary
Geographers have an important role in the foreseen and expected reform of politically institutionalized systems through the introduction of another level of local self-government. Their role is not linked merely to preparing the suitable division of Slovenia into appropriate functionally-bounded regions, since modern social changes demand from them the systematic evaluation of variant divisions from the viewpoint of the causal connection of region formation between regional development, the effects of the polycentric basis of the settlement network, and the decentralization of (public) institutions. In this paper we proceed from the hypothesis that the decentralization of institutions plays an important part in overcoming regional disparities and that their suitable organization enables the more effective exploitation of developmental potentials. Institutions are clearly a decisive lever in modern developmental policy. As much as technical innovations and a creative environment, institutions are coming to the foreground as a driving force and pivotal support for harmonious social development. The paper discusses the role, effects, and consequences of decentralizing institutions as an instrument of balanced regional development. We analyze the factors influencing the success of regionalization in the operation of the decentralization policy. Here in particular belong the formation of clear political and legal frameworks in which to begin the reform process, the precise designation of strong and, if feasible, interdisciplinary commissions for administering and coordinating the decentralization process, the formation of a concept of decentralized regionalization for Slovenia that aims at the even division of tasks and responsibilities including clear forms of reciprocal (horizontal and vertical) coordination and control among the various regional and national levels, the outline of transfers on the national level where individual administrative and legal steps mean the transfer of financial and personal authority and equipment to participants in regional communities, and finally the taking of measures to guarantee the professional ability of institutions and decentralized regional associations to undertake new tasks.
\end{abstract}

